ORIGINAL ARTICLE

\title{
Incidence and Disability-Adjusted Life Years (Dalys) Attributable to Leishmaniasis In Iran, 2013
}

\author{
Fatemeh Heydarpour ${ }^{1}$, Ali Akbari sari ${ }^{2}$, Mehdi Mohebali ${ }^{3}$, Mohammadreza \\ Shirzadi $^{4}$, Saied Bokaie ${ }^{1}$
}

\begin{abstract}
BACKGROUND: Leishmaniasis covers a range of clinical manifestations. Estimation of the burden of leishmaniasis may help guide healthcare management personnel and policy-makers in applying effective interventions. The present study aimed to calculate the incidence and burden of cutaneous and visceral leishmaniasis in Iran in 2013.

METHODS: To evaluate the epidemiological aspects of the disease in Iran, published studies over the past 20 years were searched and the viewpoints of relevant specialists in Iran were obtained. Data were collected from the Ministry of Health and from the Tehran University of Medical Sciences. To calculate years of life lost due to premature death, standard expected years of life lost was used. Standard life table of Global Burden of Disease (GBD) 2010 with the life expectancy of 86.02 years for both sexes was used to calculate the remaining potential years of life at any age from death.

RESULTS: The overall incidence of cutaneous and visceral leishmaniasis was calculated as 22 and 0.092 per 100000 population of Iran, respectively. The burden of leishmaniasis was 99.5 years: 95.34 and 4.16 years for cutaneous and visceral, respectively. Sensitivity was analyzed and deaths predicted by the Institute of Health Metrics and Evaluation added, the burden of visceral leishmaniasis was 726 years.

CONCLUSION: The share of leishmaniasis burden in Iran is lower than the global burden of the disease. GBD 2010 standard method is recommended to calculate the burden of leishmaniasis in different countries and set local priorities on the basis of these measures.

KEYWORDS: Incidence, Disability-adjusted life years, Cutaneous leishmaniasis, Visceral leishmaniasis, Iran
\end{abstract}

DOI: http://dx.doi.org/10.4314/ejhs.v26i4.10

\section{INTRODUCTION}

Leishmaniasis is a vector-borne parasitic disease caused by more than 30 species of leishmania. It covers a range of clinical manifestations, from skin damage to fatal visceral involvement (1). Although there are several forms of the disease, it may be divided into at least two larger groups of visceral and cutaneous diseases (2-4).

Visceral leishmaniasis or kala-azar typically presents as a chronic systemic disease with symptoms such as fever, hepatosplenomegaly, weight loss, fainting, and occasionally lymphadenopathy, which is the most dangerous form of the disease and, if untreated, leads to

\footnotetext{
${ }^{1}$ Department of Epidemiology, Faculty of Veterinary Medicine, University of Tehran, Tehran, Iran

${ }^{2}$ Department of Health Management and Economics, School of Public Health, Tehran University of Medical Sciences, Tehran, Iran

${ }^{3}$ Department of Medical Parasitology and Mycology, School of Ppublic Health, Tehran University of Medical Sciences, Tehran, Iran

${ }^{4}$ Department of Zoonoses,Communicable Disease Management Center, Ministry of Health,treatment and Education, Tehran, Iran

Corresponding Author: Saied Bokaie, Email: sbokaie@ut.ac.ir
} 
death (2). According to World Health Organization (WHO) estimates, 200000-400000 new cases of visceral leishmaniasis occur annually worldwide. More than $90 \%$ of new cases occur in six countries: Bangladesh, Brazil, Ethiopia, India, South Sudan, and Sudan (5). In Iran, the Mediterranean form of the disease caused by L.infantum is observed endemically in some of the north western and southern areas and sporadically in other regions (6-8).

Cutaneous leishmaniasis or oriental soreis is the most conventional form of the disease and causes skin lesions leaving permanent scars (9). According to WHO estimates, up to 1.3 million new cases occur annually worldwide, more than two-thirds of which occur in six countries: Afghanistan, Algeria, Brazil, Colombia, Iran, and Syria (5). From a clinical perspective, there are two forms of cutaneous leishmaniasis in Iran: wet or rural and dry or urban. The wet or rural forms are zoonotic and the urban form is anthroponetic (10).

In total, it has been estimated that 1.3 million new cases and 20000-30000 deaths occur annually worldwide due to diseases caused by the protozoan leishmaniai parasites (5). According to disease burden estimates, this disease is the second and fourth largest tropical disease in terms of mortality and morbidity, respectively (11).

Costly diagnosis and treatment of leishmaniasis and the comorbidity of this disease with HIV, which leads to a weaker response to treatment and more severe forms of the disease, have highlighted the importance of paying attention to this disease $(12,13)$.

Great attention has been paid to fighting this disease in Iran National Programs (29). As a result, the number of new cases has reduced in endemic regions. However, despite enormous preventive efforts, this disease has emerged in some parts of Iran (14).
Precise information about the burden of this disease can assist health decision-makers in the allocation of resources to fight the disease. Disability-adjusted life years $\left(D^{2} Y^{1}\right)$ have been used by WHO since 1990 as a more general way to quantify the burden of diseases in Global Burden of Disease $\left(\mathrm{GBD}^{2}\right)$ (15). DALY is a combined estimate of potential life years lost $\left(\mathrm{YLL}^{3}\right)$ due premature death and years lived with disability $\left(\mathrm{YLD}^{4}\right)$. A DALY shows a lost year of healthy life and total DALY or burden of disease is a value for the expression of a gap between current health status of a population and an ideal state, in which every individual of the population lives in perfect health to old age (16).

The disability-adjusted life year (DALY) is a globally accepted, nonfinancial measure of morbidity and mortality that is comparable across different conditions and regions. It can be used to determine burden of diseases and to facilitate resource allocation in different parts of the world $(17,18)$. Although WHO previously measured the global burden of leishmaniasis based on DALYs (16), the burden of the disease has never been evaluated the way we did in Iran. Since specific conditions in different regions can alter the effects of premature mortality and disability, proper policy-making and resource allocation would undoubtedly depend on accurate data about the burden of the disease within a particular area. Therefore, the present study aimed to measure the incidence rate and burden of leishmaniasis in Iran, determine the country's share in global burden of leishmaniasis in 2013, and ultimately identify the most important aspects of the burden.

\footnotetext{
${ }^{1}$ Disability adjusted life year

${ }^{2}$ Global Burden of Disease

${ }^{3}$ Years of Life Lost

${ }^{4}$ Years of Life lived with Disability
} 


\section{MATERIALS AND METHODS}

To calculate DALY, years of life lost (YLL) due to premature mortality was added to years lived with disability (YLD) of the disease, based on the following formula: DALY= YLL+YLD.

We used the standard GBD2010 method to calculate YLL, YLD, and DALY. To evaluate the epidemiological aspects of the disease in Iran, studies published over the past 20 years were searched, and viewpoints of related specialists in Iran were obtained. Iran's demographic information was obtained from the Statistical Center of the country.

YLL:

To calculate years of life lost due to premature death, standard expected years of life lost $\left(\mathrm{SEYLL}^{5}\right)$ was used. This method uses standard life expectancy to calculate years of life lost owing to premature death at each age (19). Because mortality cases of leishmaniasis are related to visceral leishmaniasis, YLL is limited to this disease. Mortality information is obtained from the Death Registration Unit, Ministry of Health, widely considered the most reliable source from which to determine causes of death.

YLL was evaluated twice: first according to the Ministry of Health report and second to mortality cases predicted by the Institute for Health Metrics and Evaluation (IHME), in which the corrected mortality cases are calculated for each predicted age and gender (20). Standard life table of GBD 2010 with the birth life expectancy of 86.02 years for both sexes was used to calculate the remaining potential years of life at any age from death (21). According to the Statistical Center of Iran in 2013, the life expectancy table was calculated as 74.49 and 71.70 for women and men, respectively (22). Therefore, we considered these values for calculating YLL and DALY.

\section{YLD}

YLD of the disease was calculated based on the number of new cases of disease during the period of disability and weight during disability. Data on the number of new cases were obtained from the Ministry of Health. To calculate the period of disease disability, the comments of five experts were collected in some tables based on age and sex groups. Finally, the course of the disease was determined considering the average opinions and comparison with published articles (23-25). In GBD 2010's study, discount rate and age weight were removed. Disability weight of this study was considered in accordance with the weights used in GBD 2010's study (26)

\section{RESULTS}

Table1 shows epidemiological information about cutaneous leishmaniasis in 2013. The number of new cases of cutaneous leishmaniasis in 2013 was 16,980, of which $9526(56.1 \%)$ and $7654(43.9 \%)$ were male and female, respectively. The overall incidence of cutaneous leishmaniasis was calculated as 22 per 100000 populations (24.6 men and 19.5women). The course of the disease varied between 2.5 and 7 months. Cutaneous leishmaniasis accounted for 95.34 of DALYS (34.95 in men and 66.53 in women), equal to that of YLD of the disease (Table 2).

According to reports, the number of new cases of visceral leishmaniasis or kala-azar was 71 in 2013 in Iran, of which 37 (52.1\%) and $34(47.9 \%)$ were male and female, respectively. The overall incidence of visceral leishmaniasis was 0.092 per 100000 patients $(0.095$ in men and 0.089 in women) and disability period varied between 2 and 3 months (Table 3 ).

The burden of visceral leishmaniasis was calculated according to data from Ministry of Health as 4.16 years (2.14 for men and 2.02 for women). Sensitivity was analyzed and deaths predicted by the Institute of Health Metrics and Evaluation added, the burden of visceral leishmaniasis was equal to 726 years (560.9 years for men and 169.3 for women) (Table 4). The above values were calculated as 591.7 using the life table of Iran (443.2 for men and 148.5 for women).

\footnotetext{
${ }^{5}$ Standard Expected Years of Life Lost
} 
Table 1: Demographic data of cutaneous leishmaniasis in Iran in 2013

\begin{tabular}{llllllll}
\hline $\begin{array}{l}\text { Age } \\
\text { group } \\
\text { (year) }\end{array}$ & \multicolumn{2}{l}{ Population(thousands) } & \multicolumn{2}{l}{ Number of cases } & \multicolumn{2}{l}{ Incidence(per100000) } & $\begin{array}{l}\text { Duration of } \\
\text { the } \\
\text { disease(year) }\end{array}$ \\
\hline$\leq 4$ & male & female & male & female & male & female & 0.52 \\
$5-14$ & 5316 & 3166 & 1152 & 1129 & 34.7 & 35.7 & 0.53 \\
$15-29$ & 11377 & 11257 & 3338 & 1727 & 29.3 & 15.3 & 0.45 \\
$30-44$ & 9565 & 9313 & 1866 & 1454 & 19.5 & 15.6 & 0.35 \\
$45-59$ & 5524 & 5502 & 930 & 980 & 16.8 & 17.8 & 0.33 \\
$60-69$ & 1684 & 1862 & 303 & 363 & 18 & 19.5 & 0.33 \\
$70-79$ & 981 & 993 & 142 & 178 & 14.5 & 17.9 & 0.30 \\
$\geq 80$ & 456 & 464 & 84 & 71 & 18.4 & 15.3 & 0.20 \\
total & 38778 & 38167 & 9526 & 7454 & 24.6 & 19.5 & \\
\hline
\end{tabular}

Table 2: YLL, YLD, DALY, and DALY/1000 related to cutaneous leishmaniasis in Iran in 2013

\begin{tabular}{|c|c|c|c|c|c|c|}
\hline \multirow{2}{*}{$\begin{array}{l}\text { Age group } \\
\text { (year) }\end{array}$} & \multicolumn{2}{|c|}{ YLDs } & \multicolumn{2}{|c|}{ DALYs } & \multicolumn{2}{|c|}{ DALY/1000 } \\
\hline & male & female & male & female & male & female \\
\hline$\leq 4$ & 7.79 & 7.63 & 7.79 & 7.63 & 0.0023 & 0.0024 \\
\hline $5-14$ & 11.79 & 10.70 & 11.79 & 10.70 & 0.0020 & 0.0019 \\
\hline $15-29$ & 19.53 & 10.10 & 19.53 & 10.10 & 0.0017 & 0.0009 \\
\hline $30-44$ & 8.49 & 6.62 & 8.49 & 6.62 & 0.0009 & 0.0007 \\
\hline $45-59$ & 3.99 & 4.20 & 3.99 & 4.20 & 0.0007 & 0.0008 \\
\hline $60-69$ & 1.30 & 1.56 & 1.30 & 1.56 & 0.0008 & 0.0008 \\
\hline $70-79$ & 0.55 & 0.69 & 0.55 & 0.69 & 0.0006 & 0.0007 \\
\hline$\geq 80$ & 0.22 & 0.18 & 0.22 & 0.18 & 0.0005 & 0.0004 \\
\hline total & 53.66 & 41.68 & 53.66 & 41.68 & 0.0014 & 0.0011 \\
\hline
\end{tabular}

Table 3: Demographic data of visceral leishmaniasis in Iran in 2013

\begin{tabular}{llllllll}
\hline $\begin{array}{l}\text { Age } \\
\text { group } \\
\text { (year) }\end{array}$ & \multicolumn{2}{l}{ Population(thousands) } & \multicolumn{2}{l}{ Number of cases } & \multicolumn{2}{l}{ Incidence(per100000) } & $\begin{array}{l}\text { Duration of } \\
\text { the } \\
\text { disease(year) }\end{array}$ \\
\hline$\leq 4$ & 3316 & female & male & female & male & female & 0.25 \\
$5-14$ & 5875 & 56166 & 22 & 28 & 0.66 & 0.88 & 0.22 \\
$15-29$ & 11377 & 11257 & 2 & 5 & 0.15 & 0.09 & 0.22 \\
$30-44$ & 9565 & 9313 & 4 & 0 & 0.02 & 0.009 & 0.22 \\
$45-59$ & 5524 & 5502 & 0 & 0 & 0 & 0 & 0.21 \\
$60-69$ & 1684 & 1862 & 0 & 0 & 0 & 0 & 0.14 \\
$70-79$ & 981 & 993 & 0 & 0 & 0 & 0 & 0.21 \\
$\geq 80$ & 456 & 464 & 0 & 0 & 0 & 0 & 0.14 \\
total & 38778 & 38167 & 37 & 34 & 0.095 & 0.089 & \\
\hline
\end{tabular}


Table 4: YLL, YLD, DALY, and DALY/1000 of visceral leishmaniasis in Iran in 2013

\begin{tabular}{|c|c|c|c|c|c|c|c|c|c|c|c|c|}
\hline \multirow{2}{*}{$\begin{array}{l}\begin{array}{c}\text { Age } \\
\text { group } \\
\text { (year) }\end{array} \\
\leq 4\end{array}$} & \multicolumn{2}{|c|}{$\begin{array}{c}\text { YLDs } \\
\text { male female }\end{array}$} & \multicolumn{2}{|c|}{$\begin{array}{l}\text { DALYs } \\
\text { male female }\end{array}$} & \multicolumn{2}{|c|}{ DALY/1000 } & \multicolumn{2}{|c|}{$\begin{array}{c}\text { YLLs }^{\mathrm{a}} \\
\text { male female }\end{array}$} & \multicolumn{2}{|c|}{$\begin{array}{c}\text { DALYs }{ }^{\mathrm{b}} \\
\text { male female }\end{array}$} & \multicolumn{2}{|c|}{ DALY $/ 1000^{c}$} \\
\hline & 1.34 & 1.7 & 1.34 & 1.7 & 0.0004 & 0.0005 & 251 & 167 & 252.2 & 168.9 & 0.0761 & 0.0534 \\
\hline $5-14$ & 0.49 & 0.3 & 0.49 & 0.3 & 0.0001 & 0.000 & 58 & - & 0.5 & 0.3 & 0.0001 & 0.0000 \\
\hline $15-29$ & 0.1 & 0.05 & 0.1 & 0.05 & - & - & 146 & - & 58 & 0.05 & 0.0051 & $0 / 0000$ \\
\hline $30-44$ & 0.2 & - & 0.2 & - & - & - & 104 & - & 146.3 & - & 0.0153 & - \\
\hline $45-59$ & - & - & - & - & - & - & - & - & 103.8 & - & 0.0188 & - \\
\hline $60-69$ & - & - & - & - & - & - & - & - & - & - & - & - \\
\hline $70-79$ & - & - & - & - & - & - & - & - & - & - & - & - \\
\hline$\geq 80$ & - & - & - & - & - & - & - & - & - & - & - & - \\
\hline total & 2.14 & 2.02 & 2.14 & 2.02 & 0.0001 & 0.0001 & 559 & 167 & 560.9 & 169.3 & 0.0145 & 0.0044 \\
\hline
\end{tabular}

YLL $^{\text {a }}$ based on death cases predicted by IHME

DALYs $^{\mathrm{b}}$ based on YLL $^{\mathrm{a}}$

DALY $/ 1000^{\mathrm{c}}$ based on DALYs ${ }^{\mathrm{b}}$

\section{DISCUSSION}

Iran is one of the six countries (Afghanistan, Algeria, Brazil, Colombia, Islamic Republic of Iran, and Syrian Arabic Republic) in which most cases of cutaneous leishmaniasis occur. The number of cutaneous leishmaniasis cases was 16,980 in 2013, lower than the number of cases reported in the same year in Afghanistan $(23,621)$, Brazil $(18,226)$, and the Arabic Republic of Syria $(71,996)$, and more than those reported in Algeria $(6,428)$ and Colombia $(9,353)(27)$. Although leishmaniasis in Iran is one of the diseases with notifiable report, underreporting of cutaneous leishmaniasis has been estimated as 2.8 to 4.6 times higher (28). Thus, the actual number of cases is expected to be between 47,544 and 78,108 persons.

It should be noted that the under-reporting rate in Colombia, Brazil, Syria, and Algeria has also been estimated at between 2.8 and 4.6 times higher. In Afghanistan, it has been estimated as 5 to 10 times higher (28).

The incidence rate of cutaneous leishmaniasis was 22 per 100000 in this study. This rate was estimated as 37 and 27 per 100000 in 2008 and 2011, respectively. More than 90\% cases of the disease were in 88 cities, and more than $80 \%$ of the cutaneous leishmaniasis cases in Iran were of the rural or zoonotic type (29).

In this study, the incidence rate was higher in men than in women, consistent with other studies $(30,31)$. One reason for this issue can be that more men than women work and rest in open environments. Moreover, men dress less heavily than women and, therefore, are more exposed to sandfly bites.

Cutaneous leishmaniasis is more important in Iran. Almost 20,000 new cases of it are reported annually (32). However except for the northwestern and southeastern regions where visceral leishmaniasis is endemic, this disease is sporadic in other regions $(6,7)$.

The number of symptomatic visceral leishmaniasis cases in 2013 was 71 with an incidence rate of 0.09 per 100000 population. Its under-reporting rate was estimated as 2 to 4 times that in Iran, bringing the actual number of the disease to between 142 and 284 persons in the country (28). Leishmaniasis, particularly its visceral type, may be associated with clinical symptoms that cause false diagnosis as an autoimmune disease and other blood diseases such as malignant lymphoma $(33,34)$. This issue in turn could be one of the reasons for the underreporting of this disease. Beause of the similar clinical symptoms of the endemic diseases such as malaria and schistosomiasis in some regions, this disease may be inaccurately diagnosed (23). According to the 2013 WHO report, the highest reported incidence of visceral leishmaniasis was in India, with 13869 reported cases, and in Brazil, with 3253 reported cases (27). In this study, similar with the results of previous studies, the highest incidence was in children less than 5 years old $(7,8)$. 
To our best knowledge, this work is the first study estimating the burden of leishmaniasis of this form in Iran. The main characteristic of studies conducted using this method is that they allow comparison between different regions and diseases (15). This study showed the exact method of calculation and the challenges of DALY estimation of leishmaniasis.

Based on the findings of this study, the burden of leishmaniasis was 99.5 years that was equal to YLD (95.34 years for cutaneous leishmaniasis and 4.16 years for visceral leishmaniasis). After analyzing the sensitivity and adding death cases predicted by IHME (The Institute for Health Metrics and Evaluation is an independent global health research center and aims to create the most complete, up-to-date roadmap to guide policymakers and donors to help people live longer and healthier), the burden of leishmaniasis was raised to 825.5. This increase was related to the rise of YLL from 0 to 726 of visceral leishmaniasis.

One of the challenges of the GBD method is the use of Standard Expected Years of Life Lost (SEYLL). In this method, standard life expectancy is used at every age to estimate the lost years caused by death at that age. Life expectancy is standard because it has been calculated on the basis of a specific life table that provides ideal life expectancy. The world's highest life expectancy is 86 years for both sexes in GBD 2010 of this standard (21). Therefore, YLL is over-estimated in countries where life expectancy is less than this maximum estimate (35).

In Iran birth life expectancy is 72 years for men and 74 years for women.Using Iran's birth life expectancy, we observed that YLL of visceral leishmaniasis was reduced from 726 to 587.5 .

As noted, DALY estimate of leishmaniasis was mainly influenced by deaths caused by visceral leishmaniasis. In these estimates, however, the psychological aspects of cutaneous leishmaniasis were not considered. Sometimes, the psychological burden of leishmaniasis is very heavy. According to the studies conducted in Afghanistan, women with skin lesions are prohibited from contact with their child in order to prevent transmission of infection. Young women with skin scars also remain unmarried (36).

In addition, in a study conducted in Colombia, leishmania scars were misused by husbands as an excuse to leave their wives (37).

Because scars of cutaneous leishmaniasis are permanent, cutaneous leishmaniasis cases may be considered chronic from the time of infection (23).

We calculated the long-term burden of cutaneous leishmaniasis considering cases from the time of infection. DALY increased from 95.34 (53.66 and 41.68 for men and women, respectively) to 13125.98 (742377 in men and 5702.2 in women, respectively). According to the life expectancy table of Iran, long-term burden was 10740.32 (5957.42 and 4782.9 in males and females, respectively).

The global burden of (cutaneous and visceral) leishmaniasis in 2010 was estimated as $3,317,000$ (16). YLL significantly impacts on DALY, and disease mortality is related to visceral leishmaniasis. However, the number of leishmaniasis cases is greater than that of cutaneous leishmaniasis in Iran. Therefore, the share of leishmaniasis burden in Iran is less than the global burden of the disease, which is approximately 0.003 . Considering the psychological burden of cutaneous leishmaniasis cases, though, and classifying the disease cases as chronic, this proportion was increased to $4 \%$.

The limitations of this study include the under-reporting of the disease. Because one of the problems of calculating leishmaniasis DALY is the calculation of its epidemiological characteristics such as disease course (38). On the other hand, one of the strengths of this study was the use of expert opinions on this disease, and of all published studies in Iran.

Life expectancy has increased significantly in Iran, and this trend may continue (39-41). Thus, it is recommended that health politicians consider the burden re-calculation of this disease over short-term intervals.

\section{REFERENCES}

1. World Health Organization. Control of the Leishmaniases. World Health Organ Tech Rep Ser.2010;(949):xii-xiii, 1-186, back cover. 
2. Desjeux P. Leishmaniasis: current situation and new perspectives. Comp ImmunolMicrobiol Infect Dis, 2004; 27: 305-18.

3. Chappuis F, Sundar S, Hailu A, et al. Visceral leishmaniasis: what are the needs for diagnosis, treatment and control?. Nature Rev Microbiol, 2007; 5: 873-82.

4. Reithinger R, Dujardin JC, Louzir H, Pirmez C, Alexander B, Brooker S. Cutaneous leishmaniasis. Lancet Infect Dis, 2007; 7: 581-96.

5. World Health Organization. Media centre , fact sheet, Leishmaniasis. [http://www.who.int/mediacentre/factsheets/ fs375/en/] Accessed Jul 30,2015.

6. Edrissian GhH. Visceral leishmaniasis in Iran and the role of serological tests in diagnosis and epidemiological studies. Journal of Kerman University of Medical Sciences, 1996; 3: 97-108.

7. Mohebali M, Edrissian GhH, Nadim A, et al. Application of direct agglutination test (DAT) for the diagnosis and seroepidemiological studies of visceral leishmanias is in Iran. Iranian J Parasitol, 2006; 1: 15- 25.

8. Mohebali M. Visceral leishmaniasis in Iran: Review of the Epidemiological and Clinical Features. Iran J Parasitol 2013; 8: 348-58.

9. Herwaldt BL. Leishmaniasis. Lancet, 1999; 354: 1191- 99.

10. Shirzadi MR, Esfahania SB, Mohebali M et al. Epidemiological status of leishmaniasis in the Islamic Republic of Iran,1983-2012. Eastern Mediterranean Health Journal, 2015; 21: 736-742.

11. Mathers CD, Ezzati M, Lopez AD. Measuring the burden of neglected tropical diseases: the global burden of disease framework. PloSNegl Trop Dis, 2007; 1: e114.

12. Alvar J, Yactayo S, Bern C.Leishmaniasis and poverty. Trends Parasitol, 2006; 22: 552-7,

13. Shafiei R, Mohebali M, Akhoundi B, et al. Emergence of co-infection of visceral leishmaniasis in HIV-positive patients in northeast Iran: A preliminary study. Travel Medicine and Infectious Disease, 2014; 12: 173-8.
14. NateghiRostami M, Saghafipour A, Vesali E. A newly emerged cutaneous leishmaniasis focus in central Iran. Int $J$ Infect Dis, 2013; 17: e1198-206.

15. Murray CJL, Lopez AD . The Global Burden of Disease: A Comprehensive Assessment of Mortality and Disability from Diseases, Injuries and Risk Factors in 1990 and Projected to 2020. Harvard University Press, 1996, 1-43.

16. Murray CJL, Lopez AD . The Global Burden of Disease: A Comprehensive Assessment of Mortality and Disability from Diseases, Injuries and Risk Factors in1990 and Projected to 2020. Harvard University Press, 1996, 1-43.

17. Murray CJ, Vos T, Lozano R, et al. Disability-adjusted life years (DALYs) for 291 diseases and injuries in 21 regions, 1990-2010: a systematic analysis for the Global Burden of Disease Study 2010. Lancet, 2012; 380: 2197 -2223.

18. Murray CJ. Quantifying the burden of disease: the technical basis for disabilityadjusted life years. Bull World Health Organ, 1994; 72: 429- 445.

19. Murray CJ, Acharya AK. Understanding DALYs disability-adjusted life years. $J$ Health Econ, 1997; 16:703 - 730.

20. World health organization Global program on Evidence for health policy: National burden of diseases: A practical Guide; second edition; October 2001.

21. Institute for Health Metrics and Evaluation, GBd Data visualization, causes of Death (COD) visualization. [http://vizhub.healthdata.org/cod/] accessed Jul 20, 2015.

22. Murray CJL, Ezzati M, Flaxman AD, et al. The Global Burden of Disease Study 2010: design, definitions, and metrics. Lancet, 2012; 380:2063-66.

23. Noorollahi T, Khodamoradi H, Abdollhnejad V. Construction of annual life table for Iran. Statistics Center of Iran. 2013: 259- 60. [Persian].

24. Reithinger R. Leishmaniases' burden of disease: ways forward for getting from speculation to reality. PLoSNegl Trop Dis, 2008; 2: e285. 
25. Talari SA, Talaei R, Shajari G, Vakili Z, Taghaviardakani A. Childhood cutaneous leishmaniasis: report of 117 cases from Iran.Korean. J Parasitol, 2006; 44: 355-60.

26. Mohammadi-Kheyrabadi K, Mohebali M, Mamishi S, Arshi Sh. EPIDEMILOGICAL CHARACTERISTICS OF KALA-AZAR IN HOSPITALIZED PATIENTS IN ARDEBIL PROVINCE. Journal of school of public Health and Institute of public Health Research, 2004; 2: 11-24.

27. Salomon JA, Vos T, Hogan DR, et al. Common values in assessing health outcomes from disease and injury: disability weights measurement study for the Global Burden of Disease Study 2010. Lancet, 2012; 380:2129-43.

28. World Health Organization. Global Health Observatory Data Repository. [http://apps.who.int/gho/data/node.main.NT DLEISH?lang=en] Accessed 9 AUG 20015.

29. Alvar J, Vélez ID, Bern C, Herrero M, Desjeux P, Cano J, Jannin J, den Boer M WHO Leishmaniasis Control Team. Leishmaniasis worldwide and global estimates of its incidence. PLoS One, 2012;7: e35671.

30. Shirzadi M R. Guidline to care of cutaneous leishmaniasis in Iran. Diseases Management Center, Ministry of Health, Treatment and Medical Education of Iran. Tehran. razenahan 2012; 1: 1-114. [Persian].

31. Kassiri H, Shemshad KH, Shojaee S. The Incidence Rate of Cutaneous Leishmaniasis in Behbahan County of Khuzestan Province, Southwest of Iran. Jundishapur Journal of Microbiology, 2013; 6: e7045.

32. Haouas N, Amer O, Ishankyty A, Alazmi A, Ishankyty I. Profile and geographical distribution of reported cutaneous leishmaniasis cases in Northwestern Saudi
Arabia, from 2010 to 2013. Asian Pac J Trop Med, 2015; 8: 287-91.

33. Diseases Management Center, Ministry of Health, Treatment and Medical Education of Iran (2002-2010) Annual Communicable Dieases Report.

34. Nozzi M, Del Torto M, Chiarelli F, Breda L. Leishmaniasis and autoimmune diseases in pediatric age. Cell Immunol, 2014; 292: 913.

35. Kawakami A, Fukunaga T, Usui M, et al. Visceral leishmaniasismis diagnosed as malignant lymphoma. Intern Med, 1996; 35: 502-6.

36. Williams A. Calculating the global burden of disease: time for a strategic reappraisal? Health Econ, 1999; 8: 1-8.

37. Reithinger, R, Aadil KH, Kolaczinski J, Mohsen M, Hami S. Social impact of leishmaniasis, Afghanistan. Emerg. Infect. Dis, 2005; 11: 634-636.

38. Velez ID, Hendrickx E, Robledo SM, Agudelo SDP. Gender and cutaneous leishmaniasis in Colombia. Cad. SaudePublica, 2001; 17: 171-180.

39. Bern C, Maguire JH, Alvar J. Complexities of assessing the disease burden attributable to leishmaniasis. PLoSNegl Trop Dis, 2008;2: e313.

40. MalekAfzali $H$. The life expectancy of Iranian men and women in 1996. Hakim Res $J, 1998 ; 2: 107-110$.

41. Pourmalek F, Abolhassani F, Naghavi M, et al. Direct estimation of life expectancy in the Islamic Republic of Iran in 2003. East MediterrHealth J, 2009; 15: 76 - 84.

42. Statistics Center of Iran. Available from: URL: http://www.amar. org.ir /Default.aspx?tabid=96\&agentType $=$ ViewT ype\&PropertyType ID=4. 